\title{
Interdisciplinary insights from instructor interviews reconciling "structure and function" in biology, biochemistry, and chemistry through the context of enzyme binding
}

\author{
Rachel Yoho ${ }^{1,2^{*}}$ (D) Tanner Foster ${ }^{2}$, Mark Urban-Lurain ${ }^{2}$, John Merrill ${ }^{3}$ and Kevin C. Haudek ${ }^{4}$
}

\begin{abstract}
Structure and function is an essential crosscutting concept in undergraduate STEM education and appears in numerous disciplines and contexts from the introductory to advanced levels. This concept is exemplified by enzyme binding, a topic spanning biology, biochemistry, and chemistry. We interviewed 13 instructors with primary instructional appointments in these fields, focusing on how they think about and also teach structure and function in their courses. We focused on how they define the component terms, "structure" and "function," their personal learning development, and how they view the interactions among these three disciplines. Overall, we found that context and terminology appear to be key factors in these conversations, as well as in the classroom. These instructors, in reflecting on their own educational development, do not consider that they developed their understanding in an undergraduate classroom. Instead, they focused on research experiences, graduate studies, postdoctoral work, or even, teaching appointments as essential points for their own knowledge. These instructors held strong opinions about interactions among the disciplines, both from the perspectives of cross-talk and what their students experience. These opinions generally center on individual instructors' opinions of other disciplines, apparent inclination to collaborate on teaching across disciplinary lines, and general preconceptions of other fields. Overall, this work has implications on the path forward for undergraduate teaching and learning of structure and function.
\end{abstract}

Keywords: Structure and function, Instructors, Undergraduate, Enzyme binding

\section{Background}

Structure and function is a key crosscutting concept in STEM

The phrase "structure and function" represents a cross -cutting concept in K-12 and undergraduate science education (National Research Council 2012). Conceptually, this topic has applications across the STEM fields and appears in the educational expectations of multiple professional societies (Yoho et al. 2018).

\footnotetext{
* Correspondence: yohora@miamioh.edu

${ }^{1}$ Department of Biology, Miami University, 212 Pearson Hall, Oxford, $\mathrm{OH}$ 45056, USA

${ }^{2}$ CREATE for STEM Institute, Michigan State University, 620 Farm Lane, East Lansing, MI 48824, USA

Full list of author information is available at the end of the article
}

Found in the Framework for K-12 Science Education as one of the seven crosscutting concepts, structure and function is described as "the way in which an object or living thing is shaped and its substructure determine many of its properties and functions" (National Research Council 2012, p.84). Within the life sciences, structure and function is listed as one of the five main core concepts for promoting biological literacy in Vision and Change (AAAS 2011). This is supported with the idea that "basic units of structure define the function of all living things" (AAAS 2011). Beyond the apparent universality of the educational expectations in the STEM fields, this concept is found in other fields of study (for example, architecture and design; Loran 1947; Mumford 1989; Yoho et al. in press) and popular articles about 
topics as widespread as business practices (Gasca 2019) and fashion and culture (Vogue 2019). As such, these ideas and component terms are not found in just STEM disciplines but also in everyday life for students at all stages and walks of life.

\section{Instructor expectations of students related to structure and function}

Additionally, this key concept is of the utmost importance in the educational development of students along the pathway from novice to expert in biology and biochemistry (ASBMB 2017; Tansey et al. 2013; Voet et al. 2003). College science faculty find the five core concepts outlined in Vision and Change to be equal to or more important than previous departmental learning goals, with $97 \%$ considering structure/function to be important for a graduating biology major to know (Brownell et al. 2014).

Recent educational trends indicate that introductory courses in the biological sciences emphasize molecular biology (including metabolism, biochemistry concepts, and genetics, among others) as opposed to organismal -level or larger scales (including ecology, plants, animal classification; Cheesman et al. 2007). Biochemistry courses are more prevalent, including requirements and electives across an increasing number of departments (Cheesman et al. 2007). Importantly, the principles of biochemistry are fundamental in other courses as departments emphasize molecular-level life sciences education. Likely, this emphasis reflects the needs of life sciences departments to prepare students for the advanced courses in their fields, many of which are highly focused on molecular biology concepts (Cheesman et al. 2007). Although present throughout the biological sciences, structure -function relationships are especially common in molecular-level education.

\section{Obstacles to student learning}

While common across the STEM disciplines, structure and function relationships present a number of instructional challenges, as the topic is present in several disciplines, may be described by varying names (Yoho et al. 2018), and the idea is broadly used in society. Importantly, students often have difficulties applying their understanding developed in a prerequisite course to new contexts in upper -level courses (Loertscher et al. 2014), similar to many topics taught in the scientific and STEM disciplines. The traditional disciplinary divisions in STEM (for example, biology and chemistry) may provide an additional confounding factor for students to apply threshold concepts identified for biochemistry (Loertscher et al. 2014). While present at multiple scales, students have the greatest difficulty applying the concepts of a structure and function relationship at the molecular level, as visualization proves a challenge (Forbes-Lorman et al. 2016), perhaps due to how complex the representation may be or how it was designed (Linenberger and Holme 2014).

Overall, students have a difficult time making connections between concepts they learned in other science disciplines and those related to biochemistry; memorization does not suffice to master the concepts (Loertscher et al. 2014). In particular, structure-function relationships exemplify these crosscutting concepts, where the ideas are presented in multiple disciplines, but students may have difficulties making connections among them. Expert understanding often includes "the ability to see principles in problem situations, whether these are represented as equations, graphs, animations, or real-world problems" (Kozma and Russell 1997). Novice students often have a difficult time sifting through course content in order to determine what information represents a key learning concept (Jenkinson and McGill 2012). Additional specificity from the instructional team is likely to help with clarifying "both the level of detail and depth of the concepts and processes" expected of the students (Tibell and Rundgren 2010). In biochemistry specifically, students must apply knowledge gained in previous courses, like introductory biology and general chemistry, to new situations (Villafañe et al. 2011). While the emphasis has shifted in instructional aims to be more at the molecular -level starting with the early courses in biology, as opposed to organismal or ecology-related topics, (Cheesman et al. 2007), a notable challenge is that these biochemistry topics are interdisciplinary (Villafañe et al. 2011). Even when students understand concepts in earlier courses, student interviews indicate that they may struggle to apply that understanding to later situations, indicating that discipline -specific education may be an additional student learning challenge (Loertscher et al. 2014). Overall, the nature of the topic of structure and function itself, the interdisciplinary content, and the reliance on previously understood concepts from discipline-specific introductory courses all provide major potential learning obstacles for students.

\section{Enzyme binding as the context for discussing structure and function}

Enzymes and enzyme binding are a well-known example of a structure and function relationship at the molecular level. These phenomena commonly are found in biochemistry education, as well as biology and chemistry courses, especially at the introductory level. Biochemistry, typically an upper-division course, requires the application of concepts learned previously in introductory level biology and chemistry studies (Villafañe et al. 2011). As a biochemistry course is a requirement or elective in most science departments (Cheesman et al. 2007), the foundational knowledge from introductory courses is of particular importance. Structure and function is a key learning concept across multiple scales within the STEM disciplines (for example, 
in anatomy and physiology or ecology). In this case however, we use enzyme binding as the connecting context -based discussion, as molecular-level concepts have gained increasing popularity in teaching and learning, as compared to these other scales (Cheesman et al. 2007).

Whether it is an introductory biology, chemistry, or biochemistry course, enzymes are only one of a large number of concepts that are typically addressed in introductory level survey courses. Balancing the educational expectations of reform calls (such as Vision and Change, AAAS 2011), departmental needs, peer instructors, and course timing becomes a challenge for instructors as the information in the life sciences continues to expand at an overwhelming rate (Jenkinson and McGill 2012). This vast expansion in knowledge has led to introductory level courses providing a mile wide and inch deep overview to students, while more recent calls-to-action have focused on limiting course content (for example, Merkel and ASM Task Force on Curriculum Guidelines for Undergraduate Microbiology 2012; Cheesman et al. 2007, Gregory et al. 2011) or providing necessary specificity (Tibell and Rundgren 2010) so that students may develop the ability to apply their knowledge across a broad range of contexts.

Today, most biochemistry textbooks present enzymatic reactions by attempting to bridge the concepts of thermodynamics and mechanistic aspects of how enzymes function (Aledo et al. 2003). Integrating these two different perspectives may represent another challenge for instructors and students. Understanding structure and function relationships in this context may also include the need to visualize three-dimensional structures and relationships (Forbes-Lorman et al. 2016; Jenkinson and McGill 2012; Kozma and Russell 1997; Tibell and Rundgren 2010), as well as understand thermodynamics and molecular binding (Aledo et al. 2003; Núnez de Castro and Alonso 1997), creating additional learning obstacles.

From a historical perspective, the framing of teaching enzymes, and biochemistry overall, has been about "fitting," either how the topics fit the interests of students or the fit of the substrate in the active site of the enzyme (Maier 1986). Overall, biochemistry is often described using a jigsaw puzzle as a metaphor of how things "fit," with scientists playing the role of solving the puzzle (Maier 1986). This sense of fitting may be extended to structure and function relationships. Lock-and-key is a historic, important representation of enzyme structure and function still used in many classrooms and textbooks. This simple representation of the complex mechanism of enzyme binding allows students to begin to understand how these molecules bind with one another in order to facilitate reactions. However, this may lead to misunderstandings of analogies or confusion between lock-and-key as an analogy and a need for specificity (Schönborn and Anderson 2009, used in the similar context of antigen -antibody binding). Born out of the lock-and-key analogy, induced fit brings together the complementarity of enzymes and their substrates, but adds flexibility for the enzyme and can be "likened to a hand in a glove" (Koshland 1995). Overall, considering protein function from the perspective of a specific three-dimensional structure has been the norm for over 100 years (Dunker and Obradovic 2001). As such, "induced fit" and analogies such as "lockand-key" and "hand in a glove" have a strong historical background in teaching and learning of structure and function related to enzymes and enzyme binding. In this work, we do not seek to analyze the impact of these important and easily recognized topics in teaching and learning, but rather document their use and discussion from these instructors' perspectives.

\section{Other terms related to the concept known as "structure and function"}

Several other topics sounding similar to, and likely representing a similar or identical concept, are found across multiple disciplines and educational reform documents. For example, "form and function" appears in the 1990s and early 2000s as "form and function are complementary aspects of objects, organisms, and systems in the natural and designed world... understanding of form and function applies to different levels of organization" (National Research Council 1996, 2012; College Board 2009). This particular discussion (found in the Framework, National Research Council 2012) touches on a number of key topics related to structure and function, for example organizations, organisms, systems, and scale, as well as bridging disciplines through the discussion of the natural and designed worlds. In the explanation of the crosscutting concept provided by the Framework, several key components are touched on, including both properties and functions of living and nonliving systems (National Research Council 2012).

In chemistry, we often may encounter phrasing such as "structure property" or "structure-property-function" (for example, Kohn et al. 2018). Additionally, these concepts are often linked with the idea of emergent properties (Cooper et al. 2012a, b; Kohn et al. 2018; Lira and Gardner 2017; Meijer et al. 2013; Meredith et al. 2006; Yoho et al. 2018). However, this can also add complexity through interactions at multiple levels of organization (for example, scale) (Lira and Gardner 2017; Yoho et al. in press). Due to numerous complexities including organization and terminology, knowledge integration may be a challenge for students across scales and disciplines (Yoho et al. 2018; Yoho et al. in press). For example, students may face difficulties in applying these concepts from previous courses (Loertscher et al. 2014) or across disciplines (Villafañe et al. 2011), we see that even the name of the topic itself may provide another potential learning barrier, as it can 
change course-to-course from the student's perspective (Yoho 2018).

In this paper, we do not attempt to analyze any deeper contextual meanings or distinctions between properties and functions. As such, we consider "properties" and "functions" to be essentially synonymous in the context of the enzyme binding-based conversations about structure and function. Importantly, this similarity is highlighted as context-dependent. In this case, the context is enzyme binding to facilitate conversation and connect to the interdisciplinary concept (not a discipline-based naming) of "structure and function." As we speak with instructors from multiple disciplinary backgrounds (biology, biochemistry, and chemistry), we consider this conceptual understanding to be both an important distinction and a key topic in the discussion of structure and function. A full analysis of the terminology and implications would be outside of the scope of this work. However, we refer readers to other literature (for example, Yoho et al. in press) in order to consider the meanings of the terms more completely. As such, we (as authors) seek to be explicit about any of our potential biases discussing this crosscutting concept from a "structure and function" background (as defined by AAAS's $\mathrm{Vi}$ sion and Change) and through our lived experiences as scientists and science education researchers from primarily biology education backgrounds. We provide additional details and context in Data collection section.

\section{Current study: structure and function teaching and learning interviews with instructors from large research universities} To gain greater insight into how undergraduate instructors in biology, biochemistry, and chemistry understand and approach this crosscutting concept, we interviewed faculty with teaching experience in introductory biology, introductory chemistry, and/or upper-level biochemistry. Our main interests centered on the instructors' understanding of the concept of structure and function. Importantly, this was not an assessment of "correct" understanding, but an attempt to grasp the contextualized and nuanced understandings that inform teaching across the three disciplines. As such, we focused on instructors' contextualized definitions of structure and function, their perceptions of their own development of conceptual understanding, and how they see their discipline in relation to the other disciplines. We sought to answer three primary research questions through these interviews with instructors from large research universities.

\section{Research questions}

1. As the principal components of the crosscutting concept, "structure and function," how do instructors define the key terms, "structure" and "function?"
2. What are the formative experiences instructors describe in their personal understanding of the "structure and function" concept?

3. How do instructors view the relationships among the biology, biochemistry, and chemistry disciplines in terms of the concept of structure and function (including as contextualized through the example of enzyme binding)?

\section{Methods}

\section{Instructor recruitment}

Interviews were solicited from instructors with teaching experience in introductory biology, chemistry, and/or an upper-level biochemistry course at Carnegie classified "doctoral universities: highest research activity" (The Carnegie Classification of Institutions of Higher Education n.d.). All instructors had teaching experience at this type of institution, however, individual instructors may have had other teaching experiences at other types of Carnegie classified institutions in their professional experience. Instructors from the professional networks and contacts of the authors of this study were recruited through in-person conversations or by email. The participants in this IRB-approved study (approval $\# \times 10-577$ ) were provided with participation information in advance of the approximately 30-minute conversation. We sought to interview several instructors from each of the three disciplines, however, we defined a minimum number of three per discipline (in each biology, chemistry, and biochemistry). For this study, the "biology" participant category had many interested participants, and as such, has the largest number. When the minimum number per discipline had been met for chemistry (with the fewest overall participants) during the time period set aside for data collection, solicitations for interviews were discontinued. While the numbers of instructors for each of the three disciplines included in this study are not equal, they are representative of the participants who volunteered their time, participated, and with the quantity also meeting the minimum threshold quantity set for the discipline by the research team.

\section{Data collection}

The interviews were all conducted using video conferencing software (Zoom Video Communications, Inc., San Jose, California) and interviewees were not compensated for their time or participation in this study. Interviews were collected from March through July of 2017. The interviews were recorded using the Zoom software and later transcribed by the first author. Analysis included only the transcription, and was limited to the audio, thereby excluding gestures and other non-verbal communication methods. Audible cues (for example, laughter) and "filler" words were transcribed in order to attempt to align with best practices in qualitative data collection and analysis (McLellan et al. 
2003). Additional information is provided in the supporting documentation, including the instructor pseudonyms, discipline, and region, the outline followed for the interviews, a description of the emergent coding process, and the consensus codebook, as well as Additional file 1 in Tables S3 through S5.

\section{Participant and institutional characteristics}

Of the 13 interviews conducted for this work, six instructors spoke from experience with teaching introductory biology, one of whom has a background in biochemistry and teaching experience in both introductory biology and biochemistry. Four instructors drew upon their experience teaching an upper-level biochemistry course. Three instructors spoke from their background teaching introductory chemistry. The biology instructors primarily have teaching responsibilities in first year introductory biology, especially cell and molecular biology courses, designed for students pursuing many different academic majors. The instructor with a background in biochemistry research and teaching, as well as teaching introductory biology, was asked to speak from the perspective of the introductory biology course primarily, while likely also drawing upon their personal experiences with biochemistry research and teaching. The four biochemistry instructors reported teaching responsibilities for upper-division courses for students in biochemistry or other majors. All instructors had teaching backgrounds at "doctoral universities: highest research activity" according to the Carnegie classification system (The Carnegie Classification of Institutions of Higher Education, n.d.). All instructors but one (community college) held current teaching appointments at doctoral universities in the Carnegie classification system (The Carnegie Classification of Institutions of Higher Education, n.d.).

In this interview, we did not ask participants to identify their gender or other identifying characteristics for the purposes of the study (and thus do not report these). Table S1 includes the demographic information relevant to the study, including the pseudonym assigned, primary teaching area or context from which they responded to the interview questions, and region of the United States in which their Carnegie Classified "doctoral institution: highest research activity" is located (The Carnegie Classification of Institutions of Higher Education, n.d.).

While we did not request and do not list specific titles or years of experience for the individual instructors, they represent a range. As the participants were recruited from the previously existing professional networks of the authors of the study, many may be familiar with science education research and/or discipline-based education research. We do not imply here that the opposite would not be the case, that individuals outside of this professional network would not have familiarity with education research. Many instructional faculty or faculty with research areas related to teaching and learning are familiar with evidence-based practices or the scholarship of teaching and learning. For example, this is evidenced further by the widespread prevalence of centers for teaching and learning at universities and the types of programs and professional development experiences that are available to faculty, especially those focused on instruction, at many institutions. Overall, we consider the instructors participating in this study to be a general representation of instructors within the defined parameters (doctoral institutions and with experience teaching in these fields) to ask the research questions, analyze their discussion, and raise questions for future research. As with any study, larger numbers or multiple institutions types could be beneficial to provide additional information or support other research questions. For the purposes of this work, we consider the study participants to be an approximation of a representative snapshot of instructors while having an appropriate quantity to allow detailed analyses of the interviews.

\section{Data analysis}

The approximately 30 to 40 -minute interviews were conducted, transcribed, and proofread by the first author of this study. The interview transcripts were de-identified during the transcription process and subsequently analyzed using QDA Miner software (Provalis Research, Montreal, Canada). The semi-structured interview protocol (see the Supporting Information for more information) was flexible to create a unique conversation with each interviewee.

An emergent coding process, based on a deductive content analysis (Moretti et al. 2011) and previously applied for crosscutting concepts in STEM education (Yoho and Rittmann 2018) was used to analyze the interviews. This qualitative content analysis method (Cho and Lee 2014) helped us to identify the themes emergent from the transcribed conversations. We found this emergent process to be particularly important, being applied to an interdisciplinary concept (for example, following that done by Yoho and Rittmann 2018), as well as the inclination to iteratively review and analyze themes between the two coders and the emergent themes with the coders' research group. Two coders independently used an emergent coding process to identify themes from the first three (chronological) interviews. One of the two coders was also the interviewer and transcriptionist. This coder has a $\mathrm{PhD}$ in an interdisciplinary biology field, with extensive training in the biological sciences, biological engineering, and chemistry subdisciplines, as well as formal training in science education and discipline-based education research. As such, this coder's terminology is "structure and function" from a background primarily in the biological sciences with extensive interdisciplinary training. In conducting the interviews, this was acknowledged and understood, as well as the potential 
influence of interviewees using other terminology. In the interviews, the interviewer would acknowledge the terminology and also adapt to the specific terminology used for the crosscutting concept by the interviewee.

The second coder was familiar with the aims of the project, the question structure for the interviews, and had discussed the interview process, but had not previously seen the interviews or transcripts. At the time, this coder was a senior-level undergraduate researcher with a background in biology and biochemistry, as well as several years of experience working in a science education research group. The two coders compared the emergent codes to create a consensus codebook used for all interviews in this study. Table $\mathrm{S} 2$ shows the results of the emergent coding process for the two coders. The rows indicate alignment between codes developed independently and highlighting on the table groups multiple related codes that were later collapsed in a consensus codebook and applied to all interviews.

In this study, all participants were assigned pseudonyms for the purposes of data analysis and presentation of results. Due to an established historical bias in gendered pronouns (Moulton et al. 1978), we refrained from using "he" for all participants or designating the participants "he" or "she." As such, we selected gender-neutral pseudonyms to use based on the first author's language and cultural background. We acknowledge a potential for the inadvertent removal of richness in the dataset by changing names and using gender-neutral pseudonyms (Clark 2006). In this work, we seek to be aware of potential biases, inclusive of identities, and have identified this as our path forward. As such, in this work we use the gender neutral "they" as a singular pronoun. Prior research indicates that the use of "they" can be considered a cognitive equivalent when working to make language more gender inclusive (Foertsch and Gernsbacher 1997). All uses of "they" in this paper are indicative of a singular pronoun, with the exception of explicit and context-cued uses of they in the plural (for example, "a majority of instructors... they..."). Importantly, the research questions and data analysis are not based upon the gender identity of the instructors. We did not seek to ask or answer questions like, "what do female-identifying biology instructors...?" As such, gender identity, while playing a strong role in the overall lived experience of the instructor, including in teaching (El-Alayli et al. 2018), or other demographic identities, do not appear in the results and discussion. As such, we limit our discussion to be discipline-specific for individuals with experience teaching at research-intensive institutions.

\section{Interrater reliability}

After the determination of the consensus codebook, the two coders independently applied these codes to the same three interviews to compare coding styles and alignment of codes. The results were discussed and changes to the code definitions and coding process were made, as necessary. After the addition of interviews from chemistry instructors, three additional codes mirroring existing codes were added to the consensus codebook: (1) interactions with biology, (2) student knowledge of biology, and (3) other interactions with biology. These codes flipped the perspective of the existing codes for the interactions with chemistry. The thirteen interviews conducted and presented in this study were analyzed with this finalized consensus codebook. The remaining ten interviews were analyzed by one coder, then the other, with previous codes visible. Any fundamental disagreements or discrepancies were discussed prior to the finalization of the coded interview set. Additional information about the coding and interview analysis can be found in the Supporting Information.

\section{Results}

Research findings

Based on our semi-structured interviews, we address our research questions and report on the instructors' understanding of structure and function from the perspectives of the component terms, their personal experiences, and their observations of the interactions among disciplines. As structure and function is approached as a crosscutting concept (cutting across multiple disciplines), we use discipline as the primary stratification of the results and discussion. As is expected for any field of study, these disciplines hold their own norms and practices and here we explore the research questions from the instructors' perspectives as situated in their training and practice.

Defining the component terms, "structure" and "function" As a key research goal in this study, instructors' understanding of structure and function relationships were assessed, not for the perception of "right or wrong," but to gain a foundational understanding of the development and teaching of this key crosscutting concept. We asked instructors to define "structure" and "function" as separate terms. Intentionally, they were not given specific constraints for their discussions of definitions, but enzyme binding was a potential contextual example in the conversation. This led to a myriad of response types and rich examples. We present the main themes arising from the conversations in our discussion here. This richness of conversation is best exemplified by Taylor's (biochemistry) response to the prompt, "Oh, that's an interesting [sic], there's a lot of ways I could go with that." As Taylor's comment indicates, the discussions varied widely based on the instructor's individual experiences and perspectives. As such, the conversations included examples, analogies, context-based definitions (both course- and 
scale-specific), and candid reflections on students' understanding of the terms.

\section{"Structure" and "function" in biology}

In general, the biology instructors built upon context -based examples or specific discussion points used in the classroom. Jamie, a less experienced introductory biology instructor, used the example of understanding the importance of "a mutation in the amino acid sequence, that's going to influence the structure of it, and then, from there, influences the function." For enzymes, Jamie feels that the students can see the "direct influence of function" in that if the structure of the enzyme is not correct, bonding to substrate cannot happen. When the interviewer re-stated that they interpreted Jamie's statements as mostly structure-focused, Jamie elaborated on the apparent lack of emphasis on function in their classes. Jamie described how "we really don't spend too much on talking about that an enzyme is a catalyst and everything. We talk a little bit about the function of it as far as like when we talked about like cell signaling." Contrastingly, Addison presented their definition of structure and function with a caveat: "very often structure-function is at the molecular level" since they were discussing a cellular and molecular biology-focused course. Addison framed their definition in a physical scale, starting from a larger scale to smaller scale when describing an "enzyme, which is a molecule, what is its structure, what is its function," with follow-up references to weak interactions and energetics. Kelsey built a discussion from the three dimensional shape to the energetics and key mechanisms of an enzyme.

Additionally, Jesse and Morgan provided specific, context-based examples of how they illustrate the concept for their students. Jesse sought to "give them examples of how there can be things that are more or less the same but you have to also appreciate that they can have subtle differences which give them different properties" and provided examples of how different types of staplers (the office supply) illustrate the concept. Interestingly, Jesse, an introductory biology instructor, used terminology that is often found common to chemistry instructors in this study, describing "properties." Jesse also described "slightly different uses and properties" and "some additional mechanism." Morgan acknowledged the inherent limitations of their teaching strategy with "I show an example, but I don't make the students do anything and and I don't think it's very effective." Morgan had described a binding pocket and how functional groups catalyze covalent linkages. Further dialogue from Morgan and Jesse can be found in Table S3. Overall, the biology instructors described cellular- and molecularlevel contexts for their classroom discussions, including for example, Kelsey describing the energetics of ATP and Addison mentioning the importance of the molecular level for structure and function. As we see in Table S3, these instructors responded and provided specific examples of abstractions of the concept describing the importance of particular scales they emphasize or examples of their preferred instructional techniques.

\section{"Structure" and "function" in biochemistry}

Overall, the biochemistry instructors provided more specific and precise definitions for "structure," which may reflect the accepted working definitions of their field. For example, Taylor, when prompted, mentioned the many possibilities for directions in that conversation. However, Taylor provided a specific definition with how "in protein science, um, structure is actually defined quite precisely. There are four levels: primary, secondary, tertiary, and quaternary. And we walk them [students] through those." Taylor also described each level succinctly before discussing additional examples provided to students in the classroom. Other biochemistry instructor definitions were based on the interview context of enzymes and enzyme binding. For example, Sidney provided a specific definition of "I guess structure is the three-dimensional orientation of the molecule in its environment." They elaborated on the definition of including this in an aqueous environment, with the exception of membrane-bound proteins. Sidney integrated the concepts of enthalpy and entropy as the factors "that determine that three-dimensional structure." From there, Sidney's description of the definition continued to include how "structure uh dictates or you know says a lot about the function" with the contexts of folding, active sites, and allosteric sites.

Also speaking about a protein folding structure, Sam mentioned that when they're talking about structure, this means "anything from the primary sequence to how that's going to affect protein folding." Similar to Sidney, Sam integrated the teaching orientation being "from more of a thermodynamics perspective." Sam linked the discussion of structure with that of function through the protein example, describing the thermodynamic influences on the shape of the protein, the amino acid locations, mutation affects. The conversation here about mutation effects on the protein continued with Sam describing "where the mutation is in the protein and how that's gonna affect or not what the protein does." This discussion point linked specifically with the discussion of function, as they showed how "we talk about function both at the protein level, for example, substrate binding, um, uh substrate affinity, um and then at the cellular organism level."

Hayden's (biochemistry) conversation focused mainly on the importance of visualization to help students understand structure and function. However, their conversation also brought out another important point. They stated that "...I say structure-function all the time in the class. And I, I think that it's become one of the 
things that the students could say it and not know what it means because I say it so much." However, Hayden also pointed out the connections with other related topics, for example, "we spend a lot of time talking about regulation, which inadvertently is teaching them about structure-function, only I don't say it's structure-function..." Overall, the biochemistry instructors provided a number of important contexts, based on the example of enzyme binding as a structure and function relationship in the interview. However, this group also made a number of connections with thermodynamics, enthalpy, entropy, and other related structure and function teaching topics.

\section{"Structure" and "function" in chemistry}

As the chemistry instructors tended to use "properties," in place of "function," we asked them to define "structure" and "properties." While these terms are not the exclusive domain of chemists, the terms may have certain discipline-specific connotations, and as such, we consider them to be similar representations of the crosscutting concept (as indicated by prior work, Yoho et al. 2018). In conversation, Charlie used their instructional progression in the classroom for their definition, starting with "structure is how the atoms are connected to each other." This created a segue to building into understanding shapes, distribution of charge, and electronegativity. Following the progression of learning goals, Charlie provided a second definition as "so structure ultimately is how the atoms are arranged and how that impacts how the electrons, the electrons are distributed over the molecule." Alex described a similar progression of concepts taught to the students, where "right at the very beginning talking about how the structure of um atomic or molecular- at the atomic or molecular level- pre-, um, defines, predicts how that substance will behave at the macroscopic level." However, Alex thinks that the understanding of these concepts involves "a long sequence" of ideas, skills, and understanding that students do not actively integrate those concepts. Alex considers that the students learn these other ideas and skills, like drawing structures, predicting three-dimensional structures, polarity, and intermolecular forces, separately as discrete concepts. However, early in the conversation Alex also mentioned how "structure-property relationships are um you know, a core idea within the course."

On the other hand, according to Charlie, "the properties side of things really ties into what I would call observables" and these observables are measurable. In general chemistry, examples of these observables would be states of matter, boiling points, melting points, solubility, and reactivity. More closely aligning with the descriptions from the biologists and chemists, Alex defines properties in a more abstract manner, where "the properties of something can originate from its structure." Additionally, Alex described the importance of connecting ideas for students:

...from my point of view, the problem [of] having students understand how the properties of something can originate from its structure, it just requires such a long sequence of events that tends to get truncated, um and therefore even though a student can do all the little bits along the way that make it, um, make it seem like they are following right along...

Similar to how Hayden (biochemistry) connected with how often "structure-function" is said in class, Alex also emphasized the importance of connecting what may be perceived by students as disparate concepts.

As a follow-up, we asked Alex more about the definitions and the differences between a biology definition and a chemistry definition of structure and function. For example, we mentioned how the structure seems to be similarly defined for the two disciplines, but the function for a biologist might be considered the role or job. Alex's response focused on predicting properties. While we report on the perceived relationships among disciplines in a later section of this work, Alex focused on defining the terminology by discipline. For example, a chemist "can predict the kinds of chemical and physical, chemical reactivity it's going to have, properties it's going to have, and you can also predict uh its physical behaviors." The main comparison between the two fields for Alex is the "grain size" of interest. Alex believes that biologists "are talking about structure-function when they're talking about the function of the enzyme. The function of the enzyme is to catalyze a reaction by binding with a substrate and weakening the bonds and making, putting it in the correct orientation and so on and so forth." The difference seen here essentially appears to be the scale of interest, or as Alex describes, the "grain size." While Alex acknowledges that both fields are interested in the "properties of the enzyme-substrate binding site," the difference is primarily in the scale.

While London (introductory chemistry) did not provide many exacting definitions, they did provide some contextualization of structure and function by comparing the scales of interest and the time dimensions. For example, London discussed "one of the ways that you can think about that is components, which I think is very popular in biology, um but I think the way that chemists think about it more is at um at a levels of organization of structure." At one point in the conversation, London discussed "fuzzy boundaries" and how might a person define a tissue, an organ, or other "sorts of layers." Additionally, London defined how the "major time dimension is associated with evolution and adaptation," while the "major time dimension [in chemistry] is associated with kinetics. And and um progress toward equilibrium." London uses the 
phrases, lock-and-key and induced fit, in the classroom. London has students compare the two mechanisms of lock-and-key and induced fit. London teaches these from a kinetics perspective and finds that the "real difficulty they have is, is the mathematics thinking with that." Of the 13 total instructors interviewed, this instructor was the only one to discuss the presentation of both lock-andkey and induced fit mechanisms for their students. The interviewer explicitly avoided the use of these terms before the instructor mentioned them, in order to investigate which were discussed unprompted. Overall, the discussion with the chemistry instructors focused on the development of understanding (from a student perspective), the scale of interest, and the the origination of properties (or "function") from the structure of the item of interest.

\section{Instructor development of their current understanding of "structure and function"}

We asked the instructors to self-identify when and how they believe they developed their own understanding of the concept of "structure and function," which now informs their teaching. While we do not attempt to provide a learning pathway for the concept, our interpretations of how these experts define structure and function, as well as when they believe they began to understand the concept, can provide insight about the expectations placed on undergraduate students today. As we, and numerous educational standards also, consider structure and function to be a key learning point and a threshold concept (as defined by Meyer and Land 2006), we consider it especially important to understand the perspective of the instructor on their learning development. As threshold concepts are based on the fundamental idea that the learning gain once attained is irreversible, experts may not remember their perspectives from early in the process (Meyer and Land 2006; Loertscher et al. 2014). Therefore, it is important to investigate instructors' expert perspectives as a key aspect to the overall study of teaching and learning of structure and function.

In conversation, several instructors provided very diplomatic, and perhaps also accurate, responses that indicated that they are developing their understanding continually, while others were more blunt in their responses. While continual development of understanding is likely to be a reality of academic research and endeavors, it may be also an artifact of a number of other factors including conscious competence in the mastery process (Ambrose et al. 2010, p.97) or imposter syndrome (Brems et al. 1994; Hutchins and Rainbolt 2017; Nedegaard 2016). The instructor responses not reflecting the likely diplomatic reply indicated opinions that were occasionally concealed in self-deprecating humor, where they made a joke about their own learning experiences. Our analysis of their self-reflection focuses on a discussion of experiences, undergraduate research, and teaching.

The key observation from our conversations is that none of the instructors interviewed from any discipline (biology, biochemistry, or chemistry) believed they developed their understanding in their undergraduate classroom. If an instructor did mention something about their undergraduate experience, it was as a diminutive. Examples include, "probably to a pretty limited extent" (Sidney, biochemistry) or "to some extent undergraduate research" (Taylor, biochemistry). Similarly, Hayden (biochemistry) "got really close" while working in a research lab as an undergraduate, but identified graduate school as the point where they developed expert understanding. Similarly, Jamie (introductory biology) was very blunt about their educational journey: "Well, I feel that just about with every concept, I knew nothing when I was an undergrad [laughter], like I had every misconception [laughter] in the book." Similar to others, Jamie pointed out that their understanding developed later. In Jamie's case, during a research-based postdoctoral position.

Instructors who associated positive learning gains for the concept of structure and function as an undergraduate (beyond "pretty limited," for example) included some discussion of the effect of undergraduate research. However, research is not the only learning experience identified by this group of instructors. Hayden (biochemistry), along with Sidney (biochemistry) and Charlie (chemistry), also identified teaching as another stage in their current understanding of structure and function, with Hayden describing this as "...then I made uh my third and final leap when I was teaching it..." Clearly, teaching the concept of structure and function helps the instructor to develop a deeper understanding of the material. However, these instructors discussed this as a key component to developing their understanding of the concept of structure and function overall. When we consider this from the perspective of a threshold concept (as defined by Meyer and Land 2006), the reflections of these instructors suggest that a key point in developing an expert-level understanding (and thus achieving a true capacity for this threshold concept) may be beyond the undergraduate level. In fact, many of these instructors overall imply that graduate, postdoctoral work, and/or instructional appointments were foundational in understanding this important interdisciplinary concept. While undergraduates may not be expected to reach expert-level understanding, the interviewed instructors largely do not identify undergraduate education as an important step where they developed any substantial understanding of the concept.

The amount of support for students to achieve learning objectives about structure and function is also important in this context. Alex (introductory chemistry) thinks that 
"that's actually a huge problem. You know, if everybody has to discover these things for themselves, it takes, it's going to take them 20 years to do it." Here, Alex is likely referring to an expert-level practitioner's understanding. The amount of detail in this understanding may vary, however. For example, Sam (biochemistry) mentioned how their students understand the concept in general, like how "the hand allows you to pick up things in a way that your leg does not." However, Sam acknowledged that "maybe I'm not digging deeply enough into my students' thinking." Sam wants their students to understand the importance of structure and function relationships across levels "and not just scale, as in large versus small, but as in many versus few." With Sam's statement about the hand and foot, they appear to be demonstrating how the differences of accessibility of tangible examples and scale play a role in students' understanding of the overarching concept. While an expert may understand the connections and similarities among structure and function relationships from the organismal level to the cellular level, for example, a novice may not.

While contrasting learning expectations, Taylor (biochemistry) described "Some of the terminology um, now I was taking these courses in the 80s, they've changed a lot." Taylor's observations reflect how instructors today are teaching in a brand new learning environment. Especially if they, and their departments, are focused on their discipline's expectations for structure and function (see Yoho et al. 2018), the learning goals are very different than the way they may have been taught in the days before Vision and Change (AAAS 2011).

\section{"Structure and function" relationships among disciplines}

While the instructors occasionally mentioned the influence of another discipline on their courses, the introductory chemistry instructors spoke extensively about the life sciences. While this may be a reflection on the interviewer's background in the life sciences, we found, however, a fundamental difference in the type of discussion. The biology instructors often discussed their students' knowledge of chemistry or mathematics or the content of their course relative to pre-requisite/co-requisite chemistry courses. The chemistry instructors more often discussed the terms that a biologist may use (in contrast to their own) or how they feel that a biologist may or may not understand a particular concept. Likely this contrast in discussion arose because of the interviewer's background or the Vision and Change quote (AAAS 2011) which used "structure and function," while the chemistry instructors tended to discuss "structure and properties" instead. While we acknowledge that these phrases are similar (Yoho et al. 2018), but may not be exactly the same (Yoho et al. in press), for the purposes of this research, the terms were used interchangeably in this part of the conversation as well. We provide greater detail regarding the instructors' responses to the Vision and Change quote in a separate future work, but here focus on the main points of interactions among the disciplines.

\section{Biology instructors' relationships with other disciplines}

When describing the way in which Jesse (introductory biology) helps students understand the nuances of enzyme binding to a correct substrate using a comparison to types of office staplers, they also acknowledged the distinction between conceptual and mechanistic understanding. As an introductory biology instructor, Jesse provides this analogy to their students to introduce a correct conceptual idea but acknowledges "that understanding that requires a far more refined understanding of chemical interactions than they have in this course." When prompted for clarification, Kelsey (introductory biology) also described their discipline's relationship with chemistry. Kelsey described how the cross-talk between biology and chemistry is mostly dependent on the faculty:

...because of the faculty that are becoming involved in the courses. Uh, we're able to increase our discussions. Um, depending on, some faculty, [pause] aren't really interested in talking about it [cross-talk between disciplines and how topics are taught]. They, they have the idea of this is what we're going to do and this is what we're doing. ...Um, but the cross-talk is increasing and we're trying to promote more of that. Um, for the discussions with chemistry, uh most of that's been sort of an informal ... although recently talking to someone from chemistry, they're open to the idea of talking about what does biology need students to learn from chemistry.

While Kelsey's discussion of a biology department and their departmental dynamics may not come as a surprise to anyone with an academic background in the STEM fields, the implications for student teaching and learning here are immense, particularly from the reliance on instructor motivations and personality dynamics to shape any interactions with other disciplines. Addison (introductory biology) responded similarly about the interactions with chemistry, but discusses a more formal setup. Addison's university has "an effort to work with the faculty" in chemistry, but "different instructors are more or less involved in that so different sections probably have more or less explicit connections." Even considering the formal university-level encouragement for interdisciplinary discussion in the processes of teaching and learning, Addison's university again likely reflects individual instructor preferences and inclinations to work across the disciplinary boundaries. However as an instructor, 
Addison says that "I am trying to be very explicit about those connections."

Students' varying chemistry backgrounds create a challenge for introductory biology instructors. For Kelsey (introductory biology), the teaching of topics in the introductory biology courses also must depend on the students' understanding of chemistry. If, for example, the students did not have a chemistry foundation, Kelsey describes being "...not sure how that's going to work if students are coming in and they maybe haven't had chemistry for years, or they did have chemistry but they didn't do that well and their chemistry is very weak." Kelsey provides the example of how this would impact topics like chemical bonds in the biology content. Jesse (introductory biology) describes a similar situation where "...many of them are learning about these chemical interactions, hydrogen bonds, ionic bonds, etc. in bio before they are learning about them in chem." Jesse describes this instructional challenge that they "run up against" as the "very wide range" of students' understanding of chemistry. Jesse finds that some students "are thinking automatically in terms of what they've learned in chemistry even if it's inorganic and we keep telling them no, this is physiology, there's water" and other students have "little chemistry" and are learning about these topics for the first time. While this may reflect the age-old conversation of course pre-requisites and co-requisites, the importance here is reflected in the specifics of teaching structure and function-related topics in the individual discipline's classroom (in this case, referring to Kelsey's and Jesse's biology classrooms).

Biochemistry instructors' relationships with other disciplines For biochemistry courses, instructors find that the students are likely to make connections and have a solid foundation for learning at this more advanced course level. We asked Taylor where they thought their students might have developed their "good understanding of like the three-dimensional aspects" that they described. Taylor thinks that organic chemistry is to credit, especially for example, how students think about atoms fitting together or understanding representations. Taylor thinks that "organic chemistry people these days do a reasonable job of transforming people into three-dimensional thinkers." The implications of this "reasonable job" done by the organic chemistry instructors may be manifested in the students' understanding. Importantly, Taylor, as a biochemistry instructor, is both relying on and attributing successes to a different discipline's (here, chemistry's) teaching of key concepts.

Sidney (biochemistry) also discusses other disciplines, but relating back to the life sciences. Sidney's says their "students often talk to me about common themes they're seeing across their courses." One example Sidney provides is a connection with genetics, where students recognize some of the molecules like DNA, RNA, and proteins "and some of them start to see that the chemistry is critical to the genetics, for example. So gene expression depends on chemistry." While Sidney's description of students making connections may be seen as a teaching victory for both Sidney and other instructors at their institution, these connections may warrant further investigation for the crosscutting concept. For example, future research may seek to explore these connections further and expand on the knowledge base in the literature of student understanding of the appearances of crosscutting concepts in multiple disciplines and any particular instructional techniques that facilitate these explicit connections.

\section{Chemistry instructors' relationships with other disciplines}

Alex (introductory chemistry), who was also very critical of the Vision and Change passage (AAAS 2011; not a main discussion point of this work), appears to be somewhat negative about the interactions between biology and chemistry. Alex describes how students cannot understand figures (for example, glycolysis) when they are shown. Alex says that:

...students until really until they've got through the end of organic chemistry don't have enough understanding to look at those chemical structures and be able to say, oh, I can predict those properties. They just can't. Um, because they can't read them. They can't decode the information that's encrypted within the structure.

Alex puts the ownership of this responsibility on the biology instructors. They describe that "this is something that I think that biologists really need to struggle with is when do you want them, and at what level do you want them, to understand what's going on? Is it, is it really all that important to know the sequence of reactions in, in the Krebs cycle? I don't think so." As with Taylor's (biochemistry) conversation, a link is drawn from this concept back to organic chemistry. While a notable difference exists in the presentation, both instructors are highlighting the importance of organic chemistry to their students' professional development.

Ultimately, Alex (chemistry) relates their discussion back to "grain size" and the scales at which the various disciplines are interested. From Alex's responses, we find that they appear to hold an understanding of the various disciplines and the relative scale at which those disciplines are interested from a somewhat fixed perspective. For example, at one point Alex describes the relative interests "...as you get into bigger and bigger molecular um grain size for example, um you are less and less interested in the atoms and the bonds themselves, you know, I think molecular biologists are interested in the potential surfaces..." 
Alex also describes the relationships between chemistry and biochemistry. Again focusing on the representations and relative scales of interest, Alex says that "we in chemistry don't get into the kind of even more complex visualizations that they do in biochemistry, but I don't think that anybody knows what those things mean anyway. You know, I don't think that, um you know, you're not going to look at one of those complex ribbon diagrams and go ah-ha! That's so-in-so."

Similarly to Alex's discussion of "grain size," London (introductory chemistry) also describes the challenges of "levels of organization" and "fuzzy boundaries" in definitions and scales of interest. London illustrates the discrepancy between biology and chemistry as "one of the ways that you can think about that is components, which I think is very popular in biology, um but I think the way that chemists think about it more is at um at a levels of organization of structure." Further strengthening the chemists' individual discussions of scales of interest, London's "fuzzy boundaries" words could link to many aspects of these conversations - boundaries among disciplines, overlaps in topics, scales of interest, or even words used to describe specific phenomena. While this is a relatively small, yet highly focused, sample set of instructors, these interviews imply a greater awareness of or propensity for chemistry instructors to discuss what they feel a biologist understands or teaches in their course.

Beyond scales and visual representations, the use of language also differs between the disciplines. While we made every effort to be conversational based on the interviewee's disciplinary background, as an expert, the interviewer's disciplinary background cannot be ignored. As in a conversation, numerous factors may influence the interview conversation, however, London (introductory chemistry) finds that "biologists talk about things in different ways then chemists do" and gives a "classic example" of discussing "ATP and getting energy from ATP." Additional information shared by the chemistry instructors included their relationships with mathematics and other chemistry courses. For example, London (chemistry) talked about the concepts of lock-and-key and induced fit and the basis in mathematical thinking. They described the need for students to be "able to make sense of um the what the equation is telling them about what the behavior will be." Similarly, Charlie (chemistry) also discussed rate data for enzymatic equations from a physical chemistry (p-chem) course. While not specifically mentioning the relationship with the discipline of mathematics, Charlie describes the comparatively less emphasis in p-chem on structure and how the discussion format ends up being "...basically the, your enzyme is a black box and you have, and you have a certain substrate and you've got, you've got um rate data." From this, we may infer that the importance of rate data may relate similarly to students' mathematical skills in the classroom. Charlie also discussed that courses "use different vocabulary, which causes confusion for students too." Overall, the chemistry instructors held strong feelings that they sought to convey to the interviewer (who has a primarily biology background). Charlie may have summarized it best with "that's a problem, we don't talk very well to each other."

\section{Discussion}

A number of rich conversations including these research topics, typically in the range of 30 to $40 \mathrm{~min}$, led to several key interpretations for our research questions. We found interesting insights on how instructors in these three disciplines define structure and function, especially through the context of enzyme binding. Additionally, their self-awareness of the development of their understanding led to many further questions on what we (educators in general) expect of students today. Finally, we observed a number of strongly held opinions about the interactions among disciplines.

\section{Reflecting on defining "structure" and "function"}

In these conversations, the instructors demonstrated the importance they place on defining structure and function. While a context (enzyme binding) was provided as part of the conversation, some instructors also spoke from a more precise and non-contextualized manner. From a broad perspective, the faculty discussed structure and function and the context of enzyme binding in the manner of an important topic for teaching and learning in their discipline, aligning with the importance of this topic found especially among biology instructors (Brownell et al. 2014). Overall, the introductory biology instructors presented the most conversation about structure-related topics, rather than function-related topics. As such, biochemistry and chemistry instructors tended to emphasize the properties or functions (used interchangeably here) with comparatively more discussions about thermodynamics, enthalpy, and entropy in discussing their definitions. In this conversation, the instructors (in general) often referred to their teaching styles and what they present in the classroom. As such, it was more difficult to differentiate between a "definition" that they might provide to their students or a definition that is part of their understanding. As these instructors likely understood that our research interests lie (at a fundamental level) in understanding teaching and learning, an implicit focus on students and the classroom ran throughout the conversations.

Terminology was a key component of the conversations. Beyond the use of functions and properties in chemistry, we found that one of the introductory biology instructors (Jesse) also used terms like "properties" and "mechanisms." Overall, this underscores the importance of terminology in the presentation of crosscutting concepts, both for the 
concept itself (structure and function, structure-properties -function, structure-properties, etc.) and also the supporting words like mechanisms. Additionally, chemistry instructors used phrasing like how something "predicts" something else (Alex) and the "observables" (Charlie). For these words, which we consider additional support for the explanation of the crosscutting concept, we also find that definitions may be essential to student understanding. Other work has found that the traditional disciplinary divisions within the STEM fields and the use of knowledge from prerequisite courses applied later in biochemistry can present particular challenges for students (Loertscher et al. 2014), especially as the prevalence of biochemistry courses and molecular life science education has increased (Cheesman et al. 2007). Especially for students from another discipline taking a chemistry course, it can be important to provide further contextualization for the use of those supporting words. As memorization does not suffice for concept mastery (Loertscher et al. 2014), clarity in what material represents key learning content is particularly important for novice students (Jenkinson and McGill 2012). As such, these discussions provided rich perspectives on terminology and what students may experience in different classrooms. In the conversation, both Alex and Charlie appear to have recognized that they were speaking with an interviewer from a primarily biology background and, as such, provided appropriate contexts and definitions through the conversation.

\section{Instructors did not develop their understanding as undergraduates}

While an introspective analysis of the development of learning obviously may be inherently problematic, the key observation is that these instructors neither feel that they developed their understanding of structure-function as undergraduates, nor found their undergraduate education to be a key step in the process. These instructors identify various experiences that contributed to their understanding of structure-function, ranging from moderate gains in undergraduate research, to much more substantial discussions of gains in graduate school and postdoctoral positions, as well as instructional appointments. Overall, this raises the question as to what learning goals are reasonable expectations for undergraduate students. If these experts who are teaching core courses now did not deeply understand the concept as an undergraduate, why would we expect today's undergraduate to understand the concepts? With this concept, we may be seeing an important manifestation of the role of the many reform documents in STEM education in the recent decade or so - where instructors may be teaching in fundamentally different ways (or expected to meet different goals) from when they learned the concepts. Obviously the principles of Vision and Change (AAAS 2011) or even the precursor documents may not have been in existence when these instructors were at the undergraduate level, depending on the age of the instructor (age was not collected). Additionally in recent years, the emphasis on molecular-level life sciences has also increased (Cheesman et al. 2007). The learning concepts today may require students to further their application of these molecular-level concepts from the introductory to advanced (biochemistry) levels in new situations (Villafañe et al. 2011). Emphasis placed on "detail and depth of contents and processes" (Tibell and Rundgren 2010) may be different than it was previously to reflect today's learning goals. As such, the expectations for their learning gains may have been completely different as a student than what they are asking of their students today. Further research is warranted on the influence of instructors' learning experience for structure and function on their teaching and learning today.

\section{Disciplinary lines reflect apparently strongly held opinions}

The instructors overall had a lot to say about their interactions with colleagues and courses in other disciplines. This came from two main areas - actual collaborations and cross-talk and their students' experience (pre-requisites, co-requisites, for example) as they navigate an undergraduate program. In these conversations, we found that the instructors' institutions may or may not have directives for disciplinary cross-talk (for example, Addison's did and Kelsey's didn't, both introductory biology). However, any cross-talk is still largely dependent on individual faculty members' particular inclinations (for example, willingness to engage in discussions of teaching and learning), or how comfortable they may be with their current practices.

While all three disciplines included some discussion of what their students see, understand, or courses they experience, the biochemistry instructors must rely strongly on the lower level courses, most likely due to the position of their usually upper-level courses. This aligns with a general understanding that knowledge integration from one educational level to another can be a challenge for students, as understanding concepts appearing in multiple disciplines (Loertscher et al. 2014). Especially for biochemistry, this can be viewed as a potential challenge or opportunity for focused efforts in teaching and learning. For example, Taylor promoted the excellent job they thought that the organic chemistry instructors had done for their students. Similarly, Sidney discussed how students would come to them and show how they were making connections surrounding the crosscutting concept of structure and function across multiple courses and disciplines.

The responses overall from instructors in these three disciplines may have some influence based on the interviewer's primarily biology background. Likely, this is seen most strongly in the chemistry instructors' statements. For 
example, we found explicit discussion of the scales of interest, language use and vocabulary, and learning objectives. This may be most notably highlighted in Alex's desire for biologists to think more about what they want their students to know. Overall, for this group of instructors, their feelings appeared to be strongly held along the disciplinary practices and instructional boundaries.

\section{Limitations and future research}

In these conversations, our findings are based on self -reporting of learning experiences and teaching. As such, there are inherent possible limitations. For example, these can be seen in the potential for interviewees to wish to be seen in the best light (social desirability; Edwards 1957) or the background of the interviewer in biology. Future research may be useful to have a similar interview done with an interviewer of a different disciplinary background for comparison. While we do not wish to extrapolate from this research to all individuals who are instructors in each of these three disciplines, we looked for common themes within and across the three disciplines. We draw comparisons among the three disciplines and, as such, may be seen to be extrapolating further. The intent, however, is to focus on the implications on teaching and learning. Finally, the interviewees were recruited from existing professional networks, self-selected, and not compensated for their time. As such, there may be an inherent selection bias, similar to those seen in other studies (Rosenthal 1965; Barnes and Brownell 2018). As with all studies of this type, additional research is highly useful.

\section{Implications on teaching and learning}

Overall, this work has several implications for teaching and learning of the crosscutting concept of structure and function at the undergraduate level. As science education researchers, we are focused on evidence-based teaching and learning, as well as active reflection on the observations, expectations, and practices of our own fields and across disciplines. Therefore, the interpretations of the interviews in this study led us to a reflection of our own classroom practices and our interpretations of the nature of structure and function as a key crosscutting concept. For example, we see several potential main educational questions arising from this work:

A. As a faculty member, what would I do differently in my practices after considering the varying influences on structure and function described by faculty across the disciplines? Or, as an administrator in higher education, what would I do differently?

B. How do we (as a science education community) address the apparent disconnect between national calls for focusing on big ideas like structure and function and these faculty members' own admission that they didn't understand the concept until graduate school or later?

C. Is structure and function so complex that expecting lower division undergraduate students to make sense of it is impossible? Or at what level of understanding do we expect undergraduates to grasp this concept?

D. How could we structure courses in order to make this crosscutting concept accessible to lower division students and those studying across disciplines? What would that look like and how could faculty be supported if this would be necessary?

While this work is unable to address all of the broad questions that it raises, we have a number of recommendations to help faculty members address this topic in their classroom, with their colleagues, and from an overall educational perspective.

As the topic is lexically ambiguous to students (based on words and phrases used in a discipline differently than everyday life, Barwell 2005; Kaplan et al. 2009; Lemke 1990; Yoho et al. in press), a number of classroom engagement and active learning strategies can be useful for beginning the conversation with students. For example, Yoho et al. (in press) and Yoho (2018) summarize a number of approaches, including providing a working definition, establishing meaning and bounds for the definition, situation-based identification questions, minute papers (Angelo and Cross 1993), and think-pair-share. Other techniques useful for lexically ambiguous topics (Kaplan et al. 2014) and potentially for function also (Yoho et al. in press) focus on differentiating statements (Lemke 1990), questioning (Adams et al. 2005), and contrasting (Lavy and Mashiach-Eizenberg 2009). However, the main teaching recommendations center around awareness in the classroom (Yoho et al. in press). In this work, we find that instructor awareness of their own learning and their students' understanding may be a necessary first step. Therefore, we recommend that instructors consider the essential crosscutting concepts and how explicitly they are approaching the conversations surrounding those in the classroom. Beyond this, administrators may wish to consider the interactions among departments and the disciplines. The essential nature of this crosscutting concept lends itself towards cross-talk and, as such, interactions among the disciplines are essential to facilitate. As students see these topics in multiple disciplines and several educational levels (Villafañe et al. 2011), this type of open communication may be essential.

Based on the interviews conducted in this study, it appears that expert-level understanding, at least in the past, may not have developed at the undergraduate level. 
At this time, there are a number of possible implications. Perhaps a true understanding of structure and function is a concept that can be mastered only beyond the undergraduate level. Or perhaps differences in educational strategies, as exemplified by Vision and Change (AAAS 2011) and related expectations are putting these at the forefront today for students and instructors alike. Some recent efforts have attempted to use Vision and Change to detail learning statements for use in undergraduate biology in hopes of aligning courses and curricula (Brownell et al. 2014; Cary et al. 2017). However, reports of the process by which development of deep understanding of structure and function by students are relatively limited. Although today's experts reflecting on their experiences did not find the topic as something that they understood to any great extent at the undergraduate level, we must work towards improvement in these areas. Ultimately, this leads back to a larger question for the science education community: what level or "depth" of understanding do we expect undergraduates to have of these important crosscutting concepts at different points in their academic career?

From these instructors' reflections, it may be necessary to continue to rethink the teaching and learning of structure and function within individual disciplines, as well as the interactions among disciplines. We find that there is a continued need to investigate this particular topic because it appears in and across disciplines, at multiple scales, and with similar terminology in everyday life. Additional integration of teaching and learning strategies may be necessary in order to ensure effective learning, especially at the introductory levels. Further research on student learning is necessary to elucidate next steps, however, faculty support is paramount. We hypothesize that beneficial faculty support may need to include opportunities for open communication among disciplines, time for designing and implementing evidence-based instructional strategies, and continued professional development time for immersion in the crosscutting educational calls to action.

\section{Conclusions}

While well understood to be a key learning concept in STEM education, structure and function (along with enzyme binding) provide an effective means to investigate the nuances of teaching and learning today. While the more experienced faculty members today may have been undergraduates in a very different learning environment (for example, pre-"active learning" days, among other educational emphases today), the importance of awareness of structure and function across the disciplines should not be understated. We found apparently strongly held opinions, whether those were for the relationships among disciplines or the instructors' own understanding. We observe that this crosscutting concept is deserving of additional investigation. For example, further work may be able to dig deeper into instructors' teaching styles, student learning when they encounter the concepts across their different courses, or the roles of supporting descriptions (for example, mechanisms and outcomes, discussed in this work) on understanding the crosscutting concept. For now, we limit our implications to speculating on the roles of disciplinary teaching and learning, as well as placing greater importance on what may be expected of undergraduate students for truly understanding crosscutting concepts.

\section{Supplementary information}

Supplementary information accompanies this paper at https://doi.org/10. 1186/s43031-019-0016-7.

Additional file 1: Table S1 Demographic information for instructors interviewed for this work. The Carnegie Classification of Institutions in Higher Education ${ }^{\oplus}$ was used for the institution classification (see: http:// carnegieclassifications.iu.edu/index.php), with all instructors having teaching experience at institutions classified as "Doctoral universities: highest research activity." The interviews are listed in chronological order with the pseudonyms used in this work and additional relevant notes. Table S2. Comparison of initial emergent coding for two coders, focusing on a detailed emergent analysis of first three chronological instructor interviews. Codes are shown in two columns for the coders, with rows indicating alignments of similar coding. Additionally, highlights are used to group codes determined to be similar, based on a later discussion. The research project name is redacted from the codes. These emergent codes were discussed to create a consensus codebook to analyze all interviews. $\left(^{*}\right)$ denotes the introduction of three codes after the development of the consensus codebook reflecting the additional interviews with introductory chemistry instructors. Table S3. Example quotes supporting RQ1 for how instructors define structure and function. Table S4. Example quotes supporting RQ2 for the self-identification of the development point for the understanding of structure -function relationships which the instructor currently has. Not all instructors were asked this question as part of the conversation, so there are a total of eight responses included here. Table S5. Example quotes supporting RQ3, focusing on discussion of interactions among the disciplines.

\section{Acknowledgments}

The authors acknowledge the feedback and helpful conversations of Kathryn Kohn and Rosa Moscarella.

\section{Authors' contribution}

RY developed the study, conducted and transcribed interviews, analyzed data, and wrote the manuscript.

TF analyzed data and contributed to manuscript.

$M U-L, J M$, and $K C H$ obtained funding for conducting the study, were formative in the intellectual shaping of the manuscript, and contributed to the study and manuscript.

All authors read and approved the final manuscript.

\section{Funding}

We gratefully acknowledge funding from the National Science Foundation (DUE grant numbers 1323162, 1347740, 0736952, and 1022653). Any opinions, findings and conclusions or recommendations expressed in this material are those of the author(s) and do not necessarily reflect the views of the NSF.

Availability of data and materials

The Supporting Information document contains the appropriate, blinded interview data to support the results, discussion, and conclusions of the 
main text. Due to data privacy, no other information is shared or posted publicly.

\section{Ethics approval and consent to participate}

The participants in this IRB-approved study (approval \#x10-577) were provided with participation information in advance of the approximately 30minute conversation.

\section{Consent for publication}

Not applicable.

\section{Competing interests}

Not applicable. The authors declare no competing interests.

\section{Author details}

'Department of Biology, Miami University, 212 Pearson Hall, Oxford, OH 45056, USA. ${ }^{2}$ CREATE for STEM Institute, Michigan State University, 620 Farm Lane, East Lansing, MI 48824, USA. ${ }^{3}$ Department of Microbiology and Molecular Genetics, Michigan State University, 100 North Kedzie Hall, East Lansing, MI 48824, USA. ${ }^{4}$ Department of Biochemistry and Molecular Biology, Michigan State University, 603 Wilson Road, East Lansing, MI 48824, USA.

Received: 23 June 2019 Accepted: 8 November 2019

Published online: 23 December 2019

\section{References}

AAAS. (2011). Vision and change in undergraduate biology education: A call to action. Washington, DC.

Adams, T. L., Thangata, F., \& King, C. (2005). "Weigh" to go! Exploring mathematical language. Mathematics Teaching in the Middle School, 10, 444448

Aledo, J. C., Lobo, C., \& Esteban del Valle, A. (2003). Energy diagrams for enzymecatalyzed reactions. Biochemistry and Molecular Biology Education, 31(4), 234236.

Ambrose, S. A., Bridges, M. W., DiPietro, M., Lovett, M. C., \& Norman, M. K. (2010). How learning works: Seven research-based principles for smart teaching. San Francisco: Wiley.

American Society for Biochemistry and Molecular Biology. (2017). Accreditation program for bachelor's degrees in biochemistry \& molecular biology. Accreditation application guide. http://www.asbmb.org/uploadedFiles/ Accreditation/Application/App\%20Guide_032817.pdf. Accessed 20 Mar 2017.

Angelo, T. A., \& Cross, K. P. (1993). Classroom assessment techniques: A handbook for college teachers. San Francisco: Jossey-Bass.

Barnes, M. E., \& Brownell, S. E. (2018). Experiences and practices of evolution instructors at Christian universities that can inform culturally competent evolution education. Science Education, 102(1), 36-59.

Barwell, R. (2005). Ambiguity in the mathematics classroom. Language and Education, 19, 117-125.

Brems, C., Baldwin, M. R., Davis, L., \& Namyniuk, L. (1994). The imposter syndrome as related to teaching evaluations and advising relationships of university faculty members. The Journal of Higher Education, 65(2), 183-193.

Brownell, S. E., Freeman, S., Wenderoth, M. P., Crowe, A. J., \& Wood, W. B. (2014), BioCore guide: A tool for interpreting the Core concepts of vision and change for biology majors. CBE-Life Sciences Education, 13(2), 200-211. https://doi.org/10.1187/cbe.13-12-0233.

Cary, T., Branchaw, J., \& Shuster, M. (2017). Conceptual elements: A detailed framework to support and assess student learning of biology core concepts. CBE-Life Science Education, 16(2), ar24. https://doi.org/10.1187/cbe.16-10-0300.

Cheesman, K., French, D., Cheesman, I., Swails, N., \& Thomas, J. (2007). Is there any common curriculum for undergraduate biology majors in the 21 st century? Bioscience, 57(6), 516-522.

Cho, J. Y., \& Lee, E. H. (2014). Reducing confusion about grounded theory and qualitative content analysis: Similarities and differences. The Qualitative Report, 19(32), 1-20.

Clark, A. (2006). Anonymising research data. Retrieved from http://eprints.ncrm.ac uk/480/1/0706_anonymising_research_data.pdf

College Board. (2009). Science college board standards for college success.

Cooper, M. M., Underwood, S. M., \& Hilley, C. Z. (2012a). Development and validation of the implicit information from Lewis structures instrument (IILSI): Do students connect structures with properties? Chemistry Education Research and Practice, 13, 195-200.
Cooper, M. M., Underwood, S. M., Hilley, C. Z., \& Klymkowsky, M. W. (2012b) Development and assessment of a molecular structure and properties learning progression. Journal of Chemical Education, 89, 1351-1357.

Dunker, A. K., \& Obradovic, Z. (2001). The protein trinity_Linking function and disorder. Nature Biotechnology, 19(9), 805.

Edwards, A. L. (1957). The social desirability variable in personality assessment and research.

El-Alayli, A., Hansen-Brown, A. A., \& Ceynar, M. (2018). Dancing backwards in high heels: Female professors experience more work demands and special favor requests, particularly from academically entitled students. Sex Roles, 79(3-4), $136-150$.

Foertsch, J., \& Gernsbacher, M. A. (1997). In search of gender neutrality: Is singular they a cognitively efficient substitute for generic he? Psychological Science, $8(2), 106-111$.

Forbes-Lorman, R. M., Harris, M. A., Chang, W. S., Dent, E. W., Nordheim, E. V., \& Franzen, M. A. (2016). Physical models have gender-specific effects on student understanding of protein structure-function relationships. Biochemistry and Molecular Biology Education, 44(4), 326-335.

Gasca, P. (2019). The 1 business function most entrepreneurs mistakenly ignore. Inc. com. May 28, 2019.

Gregory, E., Ellis, J., \& Orenstein, A. (2011). A proposal for a common minimal topic set in introductory biology courses for majors. The American Biology Teacher, 73, 16-21.

Hutchins, H. M., \& Rainbolt, H. (2017). What triggers imposter phenomenon among academic faculty? A critical incident study exploring antecedents, coping, and development opportunities. Human Resource Development International, 20(3), 194-214.

Jenkinson, J., \& McGill, G. (2012). Visualizing protein interactions and dynamics: Evolving a visual language for molecular animation. CBE - Life Sciences Education, 11, 103-110

Kaplan, J. J., Fisher, D. G., \& Rogness, N. T. (2009). Lexical ambiguity in statistics: What do students know about the words association, average, confidence, random and spread? Journal of Statistics Education, 17, 1-19.

Kaplan, J. J., Rogness, N. T., \& Fisher, D. G. (2014). Exploiting lexical ambiguity to help students understand the meaning of random. Statistics Education Research Journal, 13, 9-24.

Kohn, K. P., Underwood, S. M., \& Cooper, M. M. (2018). Connecting structureproperty and structure-function relationships across the disciplines of chemistry and biology: exploring student perceptions. CBE - Life Sciences Education, 17, ar33 1-15. https://doi.org/10.1187/cbe.18-01-0004

Koshland Jr., D. E. (1995). The key-lock theory and the induced fit theory. Angewandte Chemie International Edition in English, 33(23-24), 2375-2378.

Kozma, R. B., \& Russell, J. (1997). Multimedia and understanding: Expert and novice responses to different representations of chemical phenomena. Journal of Research in Science Teaching, 34(9), 949-968.

Lavy, I., \& Mashiach-Eizenberg, M. (2009). The interplay between spoken language and informal definitions of statistical concepts. Journal of Statistics Education, $17,3$.

Lemke, J. L. (1990). Talking science: Language, learning, and values. Norwood: Ablex Publishing Corporation.

Linenberger, K. J., \& Holme, T. A. (2014). Results of a national survey of biochemistry instructors to determine the prevalence and types of representations used during instruction and assessment. Journal of Chemical Education, 91(6), 800-806.

Lira, M. E., \& Gardner, S. M. (2017). Structure-function relations in physiology education: Where's the mechanism? Advances in Physiology Education, 41, 270-278.

Loertscher, J., Green, D., Lewis, J. E., Lin, S., \& Minderhout, V. (2014). Identification of threshold concepts for biochemistry. CBE - Life Sciences Education, 13, 516-528. https://doi.org/10.1187/cbe.14-04-0066.

Loran, E. (1947). Introduction. In H. A. Small (Ed.), Form and function: Remarks on art, design and architecture. Berkeley, CA: University of California Press.

Maier, M. L. (1986). Teaching biochemistry: A topical approach. Journal of Chemical Education, 63(3), 239-241.

McLellan, E., MacQueen, K. M., \& Neidig, J. L. (2003). Beyond the qualitative interview: Data preparation and transcription. Field Methods, 15(1), 63-84.

Meijer, M. R., Bulte, A. M., \& Pilot, A. (2013). Macro-micro thinking with structureproperty relations: Integrating 'meso-levels' in secondary education. In Concepts of matter in science education (pp. 419-436). Springer, Dordrecht.

Meredith, P., Powell, B. J., Riesz, J., Nighswander-Rempel, S. P., Pederson, M. R., \& Moore, E. G. (2006). Towards structure-property-function relationships for eumelanin. Soft Matter, 2(1), 37-44. 
Merkel, S., \& ASM Task Force on Curriculum Guidelines for Undergraduate Microbiology (2012). The development of curricular guidelines for introductory microbiology that focus on understanding. Journal of Microbiology \& Biology Education: JMBE, 13(1), 32.

Meyer, J., \& Land, R. (2006). Overcoming barriers to student understanding: Threshold concepts and troublesome knowledge. London: Routledge.

Moretti, F., van Vliet, L., Bensing, J., Deledda, G., Mazzi, M., Rimondini, M., .. \& Fletcher, I. (2011). A standardized approach to qualitative content analysis of focus group discussions from different countries. Patient education and counseling, 82(3), 420-428.

Moulton, J., Robinson, G. M., \& Elias, C. (1978). Sex bias in language use: "Neutral" pronouns that aren't. American Psychologist, 33(11), 1032.

Mumford, M. (1989). Form follows nature: The origins of American organic architecture. Journal of Architectural Education, 42, 26-37.

National Research Council. (1996). National science education standards. National Committee for Science Education Standards and Assessment. Washington, DC: National Academy Press.

National Research Council (2012). A framework for K-12 science education: Practices, crosscutting concepts, and core ideas. Washington, DC: The National Academies Press.

Nedegaard, R. (2016). Overcoming imposter syndrome: How my students trained me to teach them. Reflections: Narratives of Professional Helping, 22(4), 52-59.

Núnez de Castro, I., \& Alonso, F. J. (1997). Energy diagrams for enzyme catalysed reactions: A confusing point in the textbooks. Biochemical Education, 25(2), $87-89$.

Rosenthal, R. (1965). The volunteer subject. Human Relations, 18(4), 389-406.

Schönborn, K. J., \& Anderson, T. R. (2009). A model of factors determining students' ability to interpret external representations in biochemistry. International Journal of Science Education, 31(2), 193-232.

Tansey, J. T., Baird, T., Cox, M. M., Fox, K. M., Knight, J., Sears, D., \& Bell, E. (2013). Foundational concepts and underlying theories for majors in "biochemistry and molecular biology". Biochemistry and Molecular Biology Education, 41(5), 289-296.

The Carnegie Classification of Institutions of Higher Education. (n.d.). About Carnegie Classification. Retrieved from http://carnegieclassifications.iu.edu/

Tibell, L. A., \& Rundgren, C. J. (2010). Educational challenges of molecular life science: Characteristics and implications for education and research. CBE_Life Sciences Education, 9(1), 25-33. https://doi.org/10.1187/cbe.08-090055

Villafañe, S. M., Loertscher, J., Minderhout, V., \& Lewis, J. E. (2011). Uncovering students' incorrect ideas about foundational concepts for biochemistry. Chemistry Education Research and Practice, 12(2), 210-218.

Voet, J. G., Bell, E., Boyer, R., Boyle, J., O'Leary, M., Zimmerman, J. K., \& the Education and Professional Development Committee of the American Society for Biochemistry and Molecular Biology (2003). Mini-series: The ASBMB recommended biochemistry and molecular biology undergraduate curriculum and its implementation. Recommended curriculum for a program in biochemistry and molecular biology. Biochemistry and Molecular Biology Education, 31(3), 161-162.

Vogue (Eds.). 2019. Playing to the gallery. March 14, 2019 issue.

Yoho, R. A. (2018). A case of multiple meanings? Perspectives and tips for integrating students into specialized language use within disciplines. Oxford: The Original Lilly Conference on College Teaching http://celt.miamioh.edu/ lillycon/session_files/2019/yoho.pdf.

Yoho, R. A., \& Rittmann, B. E. (2018). Climate change and energy technologies in undergraduate introductory science textbooks. Environmental Communication, 12(6), 731-743.

Yoho, R. A., Urban-Lurain, M., Merrill, J., \& Haudek, K. C. (2018). Structure and function relationships in the educational expectations of professional societies across the STEM disciplines. Journal of College Science Teaching, 47(6), 24-31.

Yoho, R. A., Kohn, K., Urban-Lurain, M., Merrill, J., \& Haudek K. C. (in press). Exploring the meaning of function as a complex idea embedded within the crosscutting concept of structure and function. The Journal on Excellence in College Teaching.

\section{Publisher's Note}

Springer Nature remains neutral with regard to jurisdictional claims in published maps and institutional affiliations.

\section{Submit your manuscript to a SpringerOpen ${ }^{\circ}$ journal and benefit from:}

- Convenient online submission

- Rigorous peer review

- Open access: articles freely available online

- High visibility within the field

- Retaining the copyright to your article

Submit your next manuscript at $\boldsymbol{\nabla}$ springeropen.com 